\title{
Central Bank Swaps and International Dollar Illiquidity
}

\author{
Andrew K. Rose \\ Mark M. Spiegel*
}

March 14, 2012

\begin{abstract}
We derive an international centralized and decentralized market model, in the spirit of Lagos and Wright (2005), where agents can experience asset-specific illiquidity. We apply the analysis to the question of dollar illiquidity during the global financial crisis and the response through international swap arrangements conducted by the Federal Reserve during that crisis. Our results show that it is possible for a deterioration in US asset values, analogous to the meltdown experienced during the global financial crisis in US real estate and asset-backed securities, to actually result in an appreciation in the dollar exchange rate, as was observed at the crisis apex. The intuition behind this counterintuitive result is that the deterioration in other dollar asset values reduces the availability of dollars for transactions purposes. Given that dollars are required for some transactions, this raises the demand for other dollar assets, such as cash, that can substitute in providing these liquidity services. Our model predicts that the benefits of swap arrangements, such as those pursued by the Federal Reserve swap arrangements are likely to be dependent on a number of agent characteristics. The benefits are shown to be increasing in the probability of needing to transact in dollars, the opaqueness of an agent's asset portfolio, and its illiquidity.
\end{abstract}

JEL classification: E44, E58, F31, F33, F41, F42, G15, O24

Key words: illiquidity, dollar, exchange rate, decentralized market, Federal Reserve, swap arrangements

\footnotetext{
*U.C. Berkeley, Haas School of Business, arose@haas.berkeley.edu, and Federal Reserve Bank of San Francisco, mark.spiegel@sf.frb.org. Israel Malkin provided excellent research assistance. Helpful comments were received from Charles Engel, Benjamin Lester, Qian Liu, Randy Wright, and seminar participants at the NBER IFM summer institute, the NBER Conference on the Global Financial Crisis, the Bank of England Research Forum on Unconventional Monetary Policy, the Federal Reserve Bank of Chicago Summer Money Workshop, the Fourth MIFN Conference, Shandong University, Tsinghua University, and U.C. Santa Cruz. All views presented in this paper are those of authors and do not represent the views of the Federal Reserve Bank of San Francisco or Federal Reserve System.
} 


\section{Introduction}

A surprising feature of the recent global financial crisis is that while that crisis originated and was centered in the United States, at its trough the U.S. dollar actually rose in value. Prior to the crisis, many had predicted that the process of adjustment to prevailing global imbalances would include a downward adjustment in the value of the dollar [e.g. Krugman (2007)]. In contrast, during the most turbulent period of the crisis (that corresponding to the failure of Lehman Brothers in the fall of 2008) the dollar experienced a sharp appreciation.

Figure 1 plots the VIX and VSTOXX indices, which measure implied volatilities in US and European equity markets respectively against the dollar-euro exchange rate. It can be seen that the dollar exchange rate moved quite closely with volatility in equity markets over this period. Moreover, as markets returned to normalcy the can be seen by examining plots of the VIX and VSTOXX indices. Further, the decline in volatility in global financial markets at the end of the year coincided with a decline in the value of the dollar.

A similar pattern can be seen for CDS spreads. CDS spreads have been used in a companion paper to this one [Rose and Spiegel (2012)], and elsewhere in the literature [e.g. Aizenman and Pasricha (2010) and Brigo, Predescu, and Capponi (2010)] as an indicator of both default risk and market liquidity. While the channels for changes in default risk are more directly apparent, changes in liquidity would be expected to affect these as well. For example, CDS premia can be affected by overall liquidity in the bond market because the value of a bond that is delivered under default is likely to be affected by market liquidity the channels for changes in default risk are more directly apparent, changes in liquidity would be expected to affect these as well. For example, CDS premia can be affected by overall liquidity in the bond market because the value of a bond that is delivered under default is likely to be affected by market liquidity. Similarly, bid-ask spreads in the CDS market itself can be enlarged by increases in overall market illiquidity. 
As shown in Figure 2, which displays average CDS spreads for a group of OECD countries over time, the US dollar exchange rate appreciated rapidly against the euro during the period that CDS spreads were increasing rapidly, and then depreciated as CDS spreads returned to normal levels ${ }^{1}$

This pattern suggests that the appreciation of the dollar resulted in part from a flight to liquidity. The tight correlation between the VIX and the VSTOXX indices throughout the crisis suggests that it would be unreasonable to ascribe the sharp appreciation of the dollar against the euro solely to a flight to safety.

The dollar still plays a prominent role in invoicing in international transactions, even in many that do not involve agents from the United States [e.g. Goldberg and Tille (2008)]. Motivations for invoicing in dollars include reducing transactions costs [Swoboda (1968)], mitigating exposure to macroeconomic volatility [Giovannini (1988), ?] and network effects [e.g. Rey (2001)].

In response to the perceived reduction in dollar liquidity, the Federal Reserve extended dollar assets during the crisis to the central banks of major industrial countries to allow them to lend them to their domestic financial institutions experiencing dollar shortages. Obstfeld, Shambaugh, and Taylor (2009) argue that the broad injection of dollar liquidity was "... one of the most notable examples of central bank cooperation in history." Table 1 reviews the major developments of the Federal Reserve's swap program over the course of the global financial crisis.

In a companion paper, Rose and Spiegel (2012) find that auctions of dollar assets by foreign central banks disproportionately benefited countries that were more exposed to the United States through either trade linkages or asset exposure. They also find that several of the important announcements concerning the international swap programs disproportionately benefited countries exhibiting greater asset opaqueness. As such, it appears that the swap programs conducted by the Federal Reserve during the crisis had the benign impact of delivering the greatest assistance to the

\footnotetext{
${ }^{1}$ Countries included in Figure 2 are Chile, France, Greece, Hungary, Italy, Japan, Mexico, Poland, Portugal, Slovakia, South Korea, Spain, and Turkey.
} 
most distressed countries in the global economy.

This paper develops a theoretical model consistent with those observed patterns in the data. We derive an international version of the search-based asset model of Lester, Postlewaite, and Wright (2012), which is an extension of the well-known Lagos and Wright (2005) model. ${ }^{2}$ In this model, assets differ both in their returns and in their liquidity, and are valued based on both of these characteristics. The possibility of illiquidity arises because assets may be rejected by agents trading in decentralized markets. This is due to asset recognizability. Agents have differing abilities to recognize the value of an asset. Some assets are more recognizable than others, and therefore more liquid.

We derive the implications of this model for a deterioration in the returns on the "opaque asset," which we associate with the difficulties associated with asset backed securities and other opaque US assets during the global financial crisis. Our analysis demonstrates that a decline in the value of these assets raises the demand for other assets that can substitute in providing dollar liquidity services. One such asset is US currency itself, and this increased demand for US currency is shown to result in an increase in the relative value of US currency relative to the other currency; in other words, an appreciation of the nominal US dollar exchange rate similar to that which was observed at the height of the global financial crisis.

We then examine the implications of intervention in the form of dollar injections into the global economy. Such injections manifest themselves as increases in liquidity and result in increased trading opportunities in the decentralized market, improving the expected utility of an agent entering that market.

We demonstrate that the benefits of such injections are dependent on a number of agent characteristics. The benefits are shown to be increasing in the probability of needing to transact

\footnotetext{
${ }^{2}$ Geromichalos and Simonovska (2010) and Liu (2010) also develop international versions of the Lagos and Wright model.
} 
in dollars in the decentralized market, the opaqueness of the asset portfolio held by the agent, and the illiquidity of the agent. These results appear plausible, as all of these characteristics would potentially increase the dollar liquidity of the agent.

Indeed, Rose and Spiegel (2012) find that the dollar liquidity injections pursued by the Federal Reserve and major foreign central banks during the global financial crisis disproportionately benefited countries that were more exposed to the United States through either trade linkages or asset exposure, which may be associated with an increased probability of needing to transact in dollars. They also find that several of the important announcements concerning the international swap programs disproportionately benefited countries exhibiting greater asset opaqueness. However, they obtain weaker results for differences in observed illiquidity.

The remainder of this paper is divided into 8 sections. The following section introduces the model. Section 3 examines the determinants of outcomes in the centralized market. Section 4 examines the determinants of outcomes in the decentralized market. Section 5 derives the equilibrium conditions. Section 6 conducts some comparative static exercises. Section 7 applies the model to the case of a temporary injection of dollar assets, analogous to the foreign dollar swaps that were conducted by the Federal Reserve during the global financial crisis. Lastly, Section 8 concludes.

\section{Setup}

This section sets up the basic structure of our model. We extend the closed-economy country model of Lagos and Wright (2005) to a two-country international version. Moreover, as in Lester, Postlewaite, and Wright (2012), we allow agents to be unable to distinguish the value of a subset of assets.

The countries in the model are labeled $u$ and $r$, which can be interpreted as representing the United States and the rest of the world. To keep the analysis as simple as possible, we assume that 
their characteristics are identical, except where indicated. In particular, we assume that country $z$ has an overall output share of $\tau_{z} ;(z=u, r)$, where $0 \leq \tau_{z} \leq 1$ and $\tau_{u}=1-\tau_{r}$.

In each period in each country, a continuum of infinitely lived agents participate in two distinct international markets: One is a Walrasian centralized global market, and another is a decentralized market, where pairs of buyers and sellers from the two countries are randomly matched. Transactions in the decentralized market are characterized by a double-coincidence problem, which rules out barter, and anonymity, which rules out the provision of credit between matched agents. It therefore follows that a tangible medium of exchange is required for transactions to take place in the decentralized market 3

Preferences and production technologies are assumed to be identical across countries. On each date, agents from country $z(z=u, r)$ can produce a tradable homogeneous good for the centralized market, $x$, using labor, $h_{z}$, according to the production function $x_{z}=h_{z}$. The law of one price holds in this market. Utility is assumed to be concave in $x$ and negatively linear in $h$ according to $U\left(x_{z}\right)-h_{z}$ and $U^{\prime}(0)=\infty$, so that $x_{z}^{*}$, the optimal production of $x$ in each country satisfies $U\left(x_{z}^{*}\right)=1$.

Agents also produce a good, $q_{z}$, which is tradable in the international decentralized market. $q_{z}$ is produced at disutility $c\left(q_{z}\right)$, where $c^{\prime}>0, c^{\prime \prime}>0$, and $c(0)=c^{\prime}(0)=0$. Agents value $q_{z}$ according to the concave function $v\left(q_{z}\right)$, where $v^{\prime}>0, v^{\prime \prime}<0, v(0)=0$, and $v^{\prime}(0)=\infty$, so that $q_{z}^{*}$, the optimal production of $q_{z}$ satisfies $v^{\prime}\left(q_{z}\right)=c^{\prime}\left(q_{z}\right)$. To highlight the role that differences in information sets and asset illiquidity play in determining outcomes, we assume that both $x$ and $q$ are homogeneous across countries.

There are four assets in the model. Each economy has a domestic money supply, discussed in more detail below, as well as a real asset, which is like a Lucas tree. All agents have perfect

\footnotetext{
${ }^{3}$ These assumptions follow directly from Lagos and Wright (2005). As in that paper, the assumption of no barter and credit is stronger than necessary and only maintained for simplicity. It is not necessary that barter and credit are ruled out for all transactions in the decentralized market, only a portion of them.
} 
information about the value of their economy's money, which is in fixed supply. The real assets yield a dividend in the centralized market the following period. There are good assets and bad assets. Bad assets yield a zero dividend, while good assets yield a dividend of $\delta_{z}$ units of $x ; z=u, r$. Moreover, unlike money, bad assets can be produced by sellers at zero cost.

As in Lester, Postlewaite, and Wright (2012), all agents can distinguish between bad and good assets in the centralized market, but in the decentralized market only informed agents can make this distinction. Since bad assets can be produced at zero cost, sellers who do not know the value of an underlying asset will refuse to accept it at a positive price. This yields the simplification that bargaining only takes place under situations where both agents are informed. Finally, note that money can have value, although it also yields zero dividends, because it is in fixed supply and provides liquidity services. Let $\phi_{z}$ and $\psi_{z}$ represent the values of money and real assets of country $z$ in the centralized market in terms of $x$ respectively.

We focus on steady state equilibria. There is a fixed supply of trees in each country, $A_{z}$, and the supplies of both currencies grow at a constant rate, $\gamma_{z}$. Let $\widehat{k}$ represent the next period value of any variable $k$, so that $\widehat{M}_{z}=\gamma_{z} M_{z}$. Agents worldwide are assumed to share a common discount factor, $\beta$, and we assume that $\gamma_{z}>\beta$ for both countries.

It has been shown [e.g. Lagos and Rocheteau (2008)] that agents may choose to keep some of their assets out of the bargaining process in the decentralized market if they are allowed to do so, as the endowments of each agent can affect the bargaining outcome. This would be true in our model as well. However, to accommodate assets from two countries without too much complexity, we make the simplifying assumption that all assets owned by agents are brought into the decentralized market. We also assume that assets are "scarce," and therefore carry a liquidity value over their value in exchange the following day in the centralized market. 


\section{Centralized market}

This section derives the equilibrium responses of agents in the centralized market. In the centralized market, agents from country $z(z=u, r)$ choose a portfolio comprised of four assets: $m_{z, u}$ units of country $u$ currency, $m_{z, r}$ units of country $r$ currency, $a_{z, u}$ units of country $u$ real assets, and $a_{z, r}$ units of country $r$ assets. Let $y_{z}$ represent income of an agent from country $z$ in the centralized market, which satisfies

$$
y_{z}=\phi_{u} m_{z, u}+\phi_{r} m_{z, r}+\left(\delta_{u}+\psi_{r}\right) a_{z, u}+\left(\delta_{r}+\psi_{r}\right) a_{z, r}
$$

Let $W\left(y_{r}\right)$ be the value function of an agent from country $z$ in the centralized market, and define $V_{z}\left(m_{z, u}, m_{z, r}, a_{z, u}, a_{z, r}\right)$ as the value function of an agent from country $z$ in the decentralized market with portfolio $\left(m_{z, u}, m_{z, r}, a_{z, u}, a_{z, r}\right)$. The optimization problem in the centralized market for an agent from country $z$ then satisfies

$$
\max _{x_{z}, h_{z}, \widehat{m}_{z, u}, \widehat{m}_{z, r}, \widehat{a}_{z, u}, \widehat{a}_{z, r}} W\left(y_{z}\right)=\left\{U\left(x_{z}\right)-h_{z}+\beta V_{z, u}\left(\widehat{m}_{z, u}, \widehat{m}_{z, r}, \widehat{a}_{z, u}, \widehat{a}_{z, r}\right)\right\}
$$

subject to

$$
x_{z} \leq h_{z}+y_{z}-\phi_{u} \widehat{m}_{z, u}-\phi_{r} \widehat{m}_{z, r}-\psi_{u}\left(\widehat{a}_{z, u}\right)-\psi_{r}\left(\widehat{a}_{z, r}\right)+T_{z},
$$

where $T_{z}$ is a lump-sum transfer returned to private agents in country $z$ from revenues generated by money creation, $T_{z}=\left(\gamma_{z}-1\right) M_{z}$. Finally, we assume that $\gamma_{z}>1$ and, as in Lagos and Wright (2005), we assume that any constraints on $h_{z}, h_{z} \epsilon \bar{h}$ are not binding.

Agents' first order conditions satisfy 


$$
\begin{gathered}
U^{\prime}\left(x_{z}\right)=1, \\
\phi_{u} \geq \beta \frac{\partial V_{z}}{\partial \widehat{m}_{z, u}}, \\
\phi_{r} \geq \beta \frac{\partial V_{z}}{\partial \widehat{m}_{z, r}}, \\
\psi_{u} \geq \beta \frac{\partial V_{z}}{\partial \widehat{a}_{z, u}},
\end{gathered}
$$

and

$$
\psi_{r} \geq \beta \frac{\partial V_{z}}{\partial \widehat{a}_{z, r}}
$$

where the latter four conditions hold with equality when $m_{z, u}, m_{z, r}, a_{z, u}$, and $a_{z, r}$ are strictly positive, respectively. Note that $y_{z}$ does not enter into the first order conditions and $W^{\prime}\left(y_{z}\right)=1$. This is the mechanism through which the degenerate portfolio solutions are recovered each time the agents return to the centralized market in the Lagos and Wright (2005) framework.

Finally, there are four asset market clearing conditions, as the representative agent from each country holds his country's share of each asset:

$$
\begin{aligned}
& M_{u}=m_{u, u}+m_{r, u}, \\
& M_{r}=m_{u, r}+m_{r, r},
\end{aligned}
$$




$$
A_{u}=a_{u, u}+a_{u, r}
$$

and

$$
A_{r}=a_{u, r}+a_{r, r}
$$

\section{Decentralized market}

We next turn to the equilibrium in the decentralized market. In the decentralized market, agents are randomly paired into bilateral meetings. Let $z$ and $k$ represent the countries of origin of the buyer and seller respectively in the decentralized market $(z, k=u, r)$. Buyers can be paired with sellers from their own country $z=k$, or with sellers from the foreign country $z \neq k$. To highlight the possibility of liquidity differences arising across countries, we assume that sellers in the decentralized market only accept assets denominated in their domestic currencies in exchange $\mathrm{f}^{4}$

The probability of an agent from country $z$ being paired with an agent from country $k$ with a coincidence of wants is exogenous, and proportional to the share of output of country $k, \tau_{k}$. In addition, we assume that the probability of a coincidence of wants is greater among agents originating from the same country by an exogenous parameter $\alpha$, where $\alpha>1$.

Specifically, let $\lambda_{z, k}$ represent the chance of an agent from country $z$ being paired with an agent from country $k$ from whom he would want to buy, and $\widetilde{\lambda}_{z, k}$ represent the chance of an agent from country $z$ being paired in a meeting with an agent from country $k$ to whom he wants to sell. We assume that $\lambda_{z, k} \equiv \lambda \tau_{k}$ when $z \neq k$ and $\lambda_{z, k} \equiv \lambda \alpha \tau_{k}$ when $z=k$, where $\lambda$ is an exogenous

\footnotetext{
${ }^{4}$ This assumption is made for tractability. In practice, the qualitative results would go through with assets from the other country being subject to increased transactions costs. This assumption serves to simplify the decision rule, as we only need to consider two types of agents from each country, informed and uninformed.
} 
constant term. Similarly, we assume that $\widetilde{\lambda}_{z, k} \equiv \widetilde{\lambda} \tau_{k}$ when $z \neq k$ and $\widetilde{\lambda}_{z, k} \equiv \widetilde{\lambda} \alpha \tau_{k}$ when $z=k$, where $\widetilde{\lambda}$ is an exogenous constant term.

Outcomes in the decentralized market are a function of the portfolio of assets held by the buyer as well as the seller's information set. We assume that all agents from country $k$ are fully informed about the value of their domestic currency, $m_{k}(k=u, r)$. However, we assume that only a fraction of agents in country $k, \rho_{k}$, are informed about the value of the opaque asset $a_{k}$, where $0 \leq \rho_{k} \leq 1 . \rho_{k}$ is therefore also the probability that a randomly selected seller from $k$ is willing to accept both $m_{k}$ and $a_{k}$ in transactions, while $1-\rho_{k}$ represents the probability that a seller from country $k$ is uninformed about the value of $a_{k}$ and is only willing to accept $m_{k}$ as payment. As in Lester, Postlewaite, and Wright (2012), let meetings where the seller is informed about $a_{k}$ be called "type 2," and meetings where the seller is uninformed be called "type 1." The type of meeting that is taking place is known to all.

We next examine the characteristics of a type $n$ meeting $(n=1,2)$ where there is a coincidence of wants between a buyer from country $z$ and a seller from country $k$. Let $p_{z, k, n}$ represent the price paid by the buyer from country $z$ to a seller from country $k$ for $q_{z, k, n}$ units of the good in a type $n$ meeting. Let $\left(m_{z, u}, m_{z, r}, a_{z, u}, a_{z, r}\right)$ represent the buyer's portfolio, and $\left(\widetilde{m}_{k, u}, \widetilde{m}_{k, r}, \widetilde{a}_{k, u}, \widetilde{a}_{k, r}\right)$ represent the seller's portfolio, and $y_{z}$ and $y_{k}$ represent the wealth of the buyer and the seller respectively. Finally, let $\omega_{z, k, n}$ be the value of acceptable funds possessed by the buyer, i.e. those recognized by the seller and denominated in the seller's domestic currency. Given our assumptions above, $\omega_{z, k, 1}=\phi_{k} m_{z, k}$, and $\omega_{z, k, 2}=\phi_{k} m_{z, k}+\left(\psi_{k}+\delta_{k}\right) a_{z, k}$.

Assuming that the buyer has bargaining power $\theta$ and threat points are given by continuation values, the generalized Nash bargaining solution is similar to that in Lagos and Wright (2005).5

\footnotetext{
${ }^{5}$ The generalized bargaining solution is based on the assumption that the alternative to the bargaining outcome is autarky. We give buyers from either country identical bargaining power for simplicity.
} 


$$
\max _{q_{z, k, n}, p_{z, k, n}}\left[\left[v\left(q_{z, k, n}\right)+W\left(y_{z}-p_{z, k, n}\right)\right]-W_{z}\left(y_{z}\right)\right]^{\theta}\left[\left[-c\left(q_{z, k, n}\right)+W\left(y_{k}+p_{z, k, n}\right)\right]-W\left(y_{k}\right)\right]^{1-\theta}
$$

subject to $p_{z, k, n} \leq \omega_{z, k, n}$.

The first order conditions satisfy

$$
p_{z, k, n}=\frac{\theta v^{\prime}\left(q_{z, k, n}\right) c\left(q_{z, k, n}\right)+(1-\theta) v\left(q_{z, k, n}\right) c^{\prime}\left(q_{z, k, n}\right)}{\theta v^{\prime}\left(q_{z, k, n}\right)+(1-\theta) c^{\prime}\left(q_{z, k, n}\right)} \equiv \eta\left(q_{z, k, n}\right)
$$

and

$-\theta\left[-c\left(q_{z, k, n}\right)+p_{z, k, n}\right]+(1-\theta)\left[v\left(q_{z, k, n}\right)-p_{z, k, n}\right]-\varphi\left[-c\left(q_{z, k, n}\right)+p_{z, k, n}\right]^{\theta}\left[v\left(q_{z, k, n}\right)-p_{z, k, n}\right]^{(1-\theta)}=0$.

We assume that we are in the case where the liquidity constraint is binding, which implies that $p_{z, k, n}=\omega_{z, k, n}$ and $q_{z, k, n}$ satisfies 14 for $p_{z, k, n}=\omega_{z, k, n}$. Note that the terms of trade only depend on the buyer's portfolio.

The value function of an agent from country $z$ in the decentralized market is then equal to the probabilities of being a buyer in a type 1 or 2 meeting with a seller from county $k$, times the payoffs in those meetings, plus the probability of being either a seller or in a meeting with no opportunity for trade, plus a constant term, $\Psi_{z}$.

$$
V_{z}=\sum_{n=1}^{2}\left[\lambda_{u, n}\left[v\left(q_{z, u, n}\right)+W\left(y_{z}-p_{z, u, n}\right)\right]+\lambda_{r, n}\left[v\left(q_{z, r, n}\right)+W\left(y_{z}-p_{z, r, n}\right)\right]\right]+(1-\lambda) W\left(y_{z}\right)+\Psi_{k}
$$


where $\lambda_{k, 1}=\lambda_{k}\left(1-\rho_{k}\right), \lambda_{k, 2}=\lambda_{k} \rho_{k}$, and $\Psi_{k}$ represents the extra utility of an agent from country $k$ associated with being a seller relative to having no trade opportunities.

To solve for $\Psi_{k}$, let $\widetilde{q}_{z, k, n}$ and $\widetilde{p}_{z, k, n}$ represent the volume of $q$ sold to an agent from country $z$, and the proceeds of the sale respectively. $\Psi_{k}$ satisfies

$\Psi_{k}=\left\{\widetilde{\lambda}_{i}\left[-c\left(\widetilde{q}_{i, k, 1}\right)+\widetilde{p}_{i, k, 1}\right]+\widetilde{\lambda}_{j}\left[-c\left(\widetilde{q}_{j, k, 1}\right)+\widetilde{p}_{j, k, 1}\right]\right\}\left(1-\Phi_{k}\right)+\left\{\widetilde{\lambda}_{i}\left[-c\left(\widetilde{q}_{i, k, 2}\right)+\widetilde{p}_{i, k, 2}\right]+\widetilde{\lambda}_{j}\left[-c\left(\widetilde{q}_{j, k, 2}\right)+\widetilde{p}_{j, k, 2}\right]\right\} \Phi_{k}$

where $\Phi_{k}$ is an indicator variable that takes value 1 if agent $k$ is informed about $a_{k}$, and 0 otherwise.

It can be easily seen that $\Psi_{k}$ is invariant to the portfolio decision of the agent from country $k$, as it is only a function of the portfolio of the buyer, and therefore taken by the seller as given. However, note that $\Psi_{k}$ does depend on whether or not the seller is informed.

It is useful to follow Lagos and Wright (2005) in defining a function $\ell\left(q_{z, k, n}\right)$ as the liquidity premium prevailing in a type $n$ meeting with a buyer from country $z$ and a seller from country $k$. This function represents the increase in the buyer's utility from bringing an additional unit of wealth into the type $n$ meeting over and above the value of just bringing that extra unit of wealth into the next centralized market. $\ell\left(q_{z, k, n}\right)$ satisfies

$$
\ell\left(q_{z, k, n}\right) \equiv \frac{v^{\prime}\left(q_{z, k, n}\right)}{\eta^{\prime}\left(q_{z, k, n}\right)}-1
$$

Note that $\ell\left(q_{z, k, n}\right)$ is only a function of buyer characteristics. Moreover, we also follow Lagos and Wright (2005) in assuming that $\ell^{\prime}\left(q_{z, k, n}\right) \leq 0$, which holds under usual conditions.

Differentiating $V_{z}$, the first order conditions for money demand satisfy 


$$
\frac{\partial V_{z}}{\partial m_{z, u}}=\phi_{u}\left[\lambda_{u, 1} \ell\left(q_{z, u, 1}\right)+1\right]
$$

and

$$
\frac{\partial V_{z}}{\partial m_{z, r}}=\phi_{r}\left[\lambda_{z, r, 1} \ell\left(q_{z, r, 1}\right)+1\right]
$$

The first order conditions for asset demand satisfy

$$
\frac{\partial V_{z}}{\partial a_{z, u}}=\left(\psi_{u}+\delta_{u}\right)\left[\lambda_{u, 2} \ell\left(q_{z, u, 2}\right)+1\right]
$$

and

$$
\frac{\partial V_{z}}{\partial a_{z, r}}=\left(\psi_{r}+\delta_{r}\right)\left[\lambda_{r, 2} \ell\left(q_{z, r, 2}\right)+1\right]
$$

Combining 19, 20, 21, and 22 with the centralized market solution conditions, we obtain solutions for the conditions determining portfolio demand. The demand for currency $u$ satisfies

$$
\phi_{u} \geq \beta \widehat{\phi}_{u}\left[\lambda_{u, 1} \ell\left(\widehat{q}_{z, u, 1}\right)+\lambda_{u, 2} \ell\left(\widehat{q}_{z, u, 2}\right)+1\right]
$$

while the demand for currency $r$ satisfies

$$
\phi_{r} \geq \beta \widehat{\phi}_{r}\left[\lambda_{r, 1} \ell\left(\widehat{q}_{z, r, 1}\right)+\lambda_{r, 2} \ell\left(\widehat{q}_{z, r, 2}\right)+1\right],
$$

where the conditions hold with equality if $\widehat{m_{u}}$ and $\widehat{m_{r}}$ are strictly positive, respectively.

The demand for assets satisfy 


$$
\psi_{u} \geq \beta\left(\widehat{\psi}_{u}+\delta_{u}\right)\left[\lambda_{u, 2} \ell\left(\widehat{q}_{z, u, 2}\right)+1\right]
$$

and

$$
\psi_{r} \geq \beta\left(\widehat{\psi}_{r}+\delta_{r}\right)\left[\lambda_{r, 2} \ell\left(\widehat{q}_{z, r, 2}\right)+1\right]
$$

where the conditions again hold with equality if $\widehat{a_{u}}$ and $\widehat{a_{r}}$ are strictly positive, respectively.

\section{Equilibrium}

Equilibrium is defined as a solution for asset holdings by agents from $u$ and $r,\left(m_{u, u}, m_{u, r}, a_{u, u}, a_{u, r}\right)$, and $\left(m_{r, u}, m_{r, r}, a_{r, u}, a_{r, r}\right)$, asset prices $\left(\phi_{u}, \phi_{r}, \psi_{u}, \psi_{r}\right)$, the terms of trade in the decentralized markets, $\left(p_{k}, q_{k}\right) ;(k=u, r)$, and the leisure choices, $\left(x_{u}, h_{u}\right)$ and $\left(x_{r}, h_{r}\right)$, which satisfy the maximization conditions of each agent, the bargaining solutions in the decentralized markets, and market clearing in the centralized market.

In the steady state equilibrium, real variables are constant over time, so that $q_{z}=\widehat{q_{z}}, \phi_{z} m_{z}$

and $\psi_{z} a_{z}$ are constant, and $\phi_{z}$ and $M_{z}$ grow at a constant rate $\gamma_{z}(z=u, r)$. The steady state versions of money demand equations 23 and 24 satisfy

$$
\frac{\gamma-\beta}{\beta \lambda_{u}} \geq\left(1-\rho_{u}\right) \ell\left(q_{z, u, 1}\right)+\rho_{u} \ell\left(q_{z, u, 2}\right)
$$

and

$$
\frac{\gamma-\beta}{\beta \lambda_{r}} \geq\left(1-\rho_{r}\right) \ell\left(q_{z, r, 1}\right)+\rho_{r} \ell\left(q_{z, r, 2}\right)
$$


where the conditions hold with equality for agents that hold strictly positive levels of $m_{u}$ and $m_{r}$ respectively.

The demand for assets satisfy

$$
\frac{(1-\beta) \psi_{u}-\beta \delta_{u}}{\beta\left(\psi_{u}+\delta_{u}\right) \lambda_{u}}=\rho_{u} \ell\left(q_{z, u, 2}\right)
$$

and

$$
\frac{(1-\beta) \psi_{r}-\beta \delta_{r}}{\beta\left(\psi_{r}+\delta_{r}\right) \lambda_{r}}=\rho_{r} \ell\left(q_{z, r, 2}\right)
$$

where the conditions hold with equality for agents that hold strictly positive levels of $a_{u}$ and $a_{r}$ respectively.

The equilibrium solution is described as the following proposition:

Proposition 1 There exists a unique steady state monetary equilibrium for which $\left(q_{z, u, 1}\right.$ and $q_{z, u, 2}$ satisfy 27 and 29. $\left(q_{z, r, 1}\right)$ and $\left(q_{z, r, 2}\right)$ satisfy 28 and 30 , prices satisfy $\phi_{k}=\eta\left(q_{z, k, 1}\right) / M_{z, k}$ and $\psi_{k}=\left[\eta\left(q_{z, k, 2}-\eta\left(q_{z, k, 1}\right] / A_{z, k}-\delta_{k}\right.\right.$ where $(z, k=u, r)$.

Proof:

First, we demonstrate that the equilibrium prices are as stated in the proposition. Consider a type 1 meeting with an agent from country $k$ in which the agent from country $z$ wants to buy $z, k=i, j$. By definition, the buyer can only use country $k$ currency for the purchase in a type 1 meeting. Since the amount of the purchase in a type 1 meeting is equal to $\eta\left(q_{z, k, 1}\right)$ by equation 14. the value of currency holdings in this meeting is $M_{z, k}$ is equal to $\phi_{k}=\eta\left(q_{z, k, 1}\right) / M_{z, k}$.

Next, consider a type 2 meeting with the same pair of agents. In this meeting, the agent from country $k$ will accept country $k$ assets as well as currency. Since the buyer is illiquid, he 
uses all of his assets and currency in the transaction. It follows that $\eta\left(q_{k, z, 1}\right)$ of the transaction is financed by currency and $\left[\eta\left(q_{z, k, 2}\right)-\eta\left(q_{z, k, 1}\right)\right]$ is left to be financed from the dividends earned on holdings of asset $A_{z}, \delta_{k} A_{z, k}$, as well as the sale of those holdings, valued at $\psi_{k} A_{z, k}$. It follows that $\delta_{k} A_{z, k}+\psi_{k} A_{z, k}=\left[\eta\left(q_{z, k, 2}\right)-\eta\left(q_{z, k, 1}\right)\right]$, which can be solved for $\psi_{k}$ as stated in Proposition 1.

The existence of an interior solution for $\psi_{u}$ and $\psi_{r}$ can be seen from equations 28 and 30 . The limit of the left-hand side of either equation as $\psi_{k} \rightarrow \infty(k=u, r)$ is -1 , which precludes either equation from holding with equality. Similarly, as $\psi_{k} \rightarrow 0$ the left-hand side of either equation is $\infty$. Differentiating the left hand sides of 28 and 30 with respect to $\psi_{k}(k=u, r)$, we obtain

$$
\frac{\partial}{\partial \psi_{k}}=\frac{\lambda_{k} \delta_{k}}{\left[\beta\left(\psi_{k}+\delta_{k}\right) \lambda_{k}\right]^{2}} \geq 0,(k=u, r)
$$

which combined with the fact that the right-hand sides of 28 and 30 are decreasing in $\psi_{k}$ by inspection (higher asset values raise liquidity, reducing the liquidity premium $\left.\ell\left(q_{z, k, 2}\right)(k=u, r)\right)$ guarantees uniqueness.

\section{Comparative statics}

We next turn to the comparative static results associated with our equilibrium. First, we investigate the implications of a permanent decline in the dividend stream on the country $u$ risky asset, $\delta_{u}$, which may be broadly associated with the real estate market decline in the United States during the global financial crisis.

By equation 29, the change in $\psi_{u}$ with a decline in $\delta_{u}$ satisfies

$$
\frac{\partial \psi_{u}}{\partial \delta_{u}}=\frac{\delta_{u}-\beta\left(\psi_{u}+\delta_{u}\right) \lambda_{u} \rho_{u} \ell^{\prime}\left(q_{z, u, 2}\right)}{\psi_{u}-\beta\left(\psi_{u}+\delta_{u}\right) \lambda_{u} \rho_{u} \ell^{\prime}\left(q_{z, u, 2}\right)}
$$


The numerator of equation 32 is unambiguously positive, but the denominator is ambiguous in sign. The necessary condition for $\partial \psi_{u} / \partial \delta_{u} \geq 0$ is that $\ell^{\prime}\left(q_{z, u, 2}\right)$ is not "too large". We require

$$
\psi_{u} \geq \beta\left(\psi_{u}+\delta_{u}\right) \lambda_{u} \rho_{u} \ell^{\prime}\left(q_{z, u, 2}\right)
$$

In contrast, it can be seen by inspection of equation $30 \psi_{r}$ is invariant to a decline in $\delta_{u}$.

Substituting from equation 29 into equation 27 we obtain

$$
\gamma-\beta \geq \beta \lambda_{u}\left(1-\rho_{u}\right) \ell\left(q_{z, u, 1}\right)+\frac{\psi_{u}}{\left(\psi_{u}+\delta_{u}\right)}
$$

In the steady state the level of real balances taken by an agent from country $z$ into the decentralized market, $\phi_{u} m_{z, u}$, will be a constant. However, the steady state value of $\phi_{u} m_{z, u}$ will be endogenous, and in particular a function $\delta_{u}$. Totally differentiating with respect to $\phi_{u} m_{z, u}$ and $\delta_{u}$ yields

$$
\frac{\partial \phi_{u} m_{z, u}}{\partial \delta_{u}}=\frac{\psi_{u}+\delta_{u} \frac{\partial \psi_{u}}{\partial \delta_{u}}}{\left(\psi_{u}+\delta_{u}\right)^{2} \beta \lambda_{u}\left(1-\rho_{u}\right) \ell^{\prime}\left(q_{z, u, 1}\right) I\left\{\widehat{\omega}_{z, u, 1}<\eta\left(q^{*}\right)\right\}} \leq 0,
$$

as $\frac{\partial \psi_{u}}{\partial \delta_{u}}$ can be signed as positive given satisfaction of condition 33 .

Again, in contrast, it can be seen by inspection of equation 28, combined with the fact that $\psi_{r}$ is invariant to a decline in $\delta_{u}$, that $\phi_{r} m_{z, r}$ will be invariant to a change in $\delta_{u}$. This leads to our second proposition:

Proposition 2 Given condition 33, a decline in the dividend stream of the risky asset from country $u$ will lead to an appreciation in country $u$ 's exchange rate, $\phi_{u} / \phi_{r}$.

Proof: 
We have four equations and four unknowns for the price and allocations of country $i$ assets. The four equations are

$$
\begin{gathered}
\Lambda_{1} \equiv \lambda_{u, u, 1} \ell\left(q_{u, u, 1}\right)+\lambda_{u, u, 2} \ell\left(q_{u, u, 2}\right)-\frac{1-\beta \gamma_{u}}{\beta \gamma_{u}}=0 \\
\Lambda_{2} \equiv \lambda_{r, u, 1} \ell\left(q_{r, u, 1}\right)+\lambda_{r, u, 2} \ell\left(q_{r, u, 2}\right)-\frac{1-\beta \gamma_{r}}{\beta \gamma_{r}}=0 \\
\Lambda_{3} \equiv \lambda_{u, u, 2} \ell\left(q_{u, u, 2}\right)-\frac{\psi_{u}-\beta\left(\psi_{u}+\delta_{u}\right)}{\beta\left(\psi_{u}+\delta_{u}\right)}=0 \\
\Lambda_{4} \equiv \lambda_{r, u, 2} \ell\left(q_{r, u, 2}\right) I\left\{\omega_{r, u, 2}<\eta(q *)\right\}-\frac{\psi_{u}-\beta\left(\psi_{u}+\delta_{u}\right)}{\beta\left(\psi_{u}+\delta_{u}\right)}=0
\end{gathered}
$$

To solve for the comparative static equations, recall that $\omega_{z, k, 1}=\varphi_{k} m_{z, k}$ and $\omega_{z, k, 2}=\varphi_{k} m_{z, k}+$ $\left(\psi_{k}+\delta_{k}\right) a_{z, k}$, and

$$
\frac{d q}{d \omega}=\frac{1}{\eta^{\prime}(q)}=\frac{\left[\theta v^{\prime}+(1-\theta) c^{\prime}\right]^{2}}{\theta(1-\theta)(v-c)\left(v^{\prime} c^{\prime \prime}-v^{\prime \prime} c^{\prime}\right)+\theta\left(v^{\prime}\right)^{2} c^{\prime}+(1-\theta) v^{\prime}\left(c^{\prime}\right)^{2}} \geq 0
$$

Define the following

$$
\begin{gathered}
\sigma_{u, 1} \equiv \lambda_{u, u, 1} \ell^{\prime}\left(q_{u, u, 1}\right) \frac{d q_{u, u, 1}}{d \omega}<0 \\
\sigma_{u, 2} \equiv \lambda_{u, u, 2} \ell^{\prime}\left(q_{u, u, 2}\right) \frac{d q_{u, u, 2}}{d \omega}<0
\end{gathered}
$$




$$
\begin{gathered}
\sigma_{r, 1} \equiv \lambda_{r, u, 1} \ell^{\prime}\left(q_{r, u, 1}\right) \frac{d q_{r, u, 1}}{d \omega}<0 \\
\sigma_{r, 2} \equiv \lambda_{r, u, 2} \ell^{\prime}\left(q_{r, u, 2}\right) \frac{d q_{r, u, 2}}{d \omega}<0
\end{gathered}
$$

Then the comparative static equations of the system satisfy

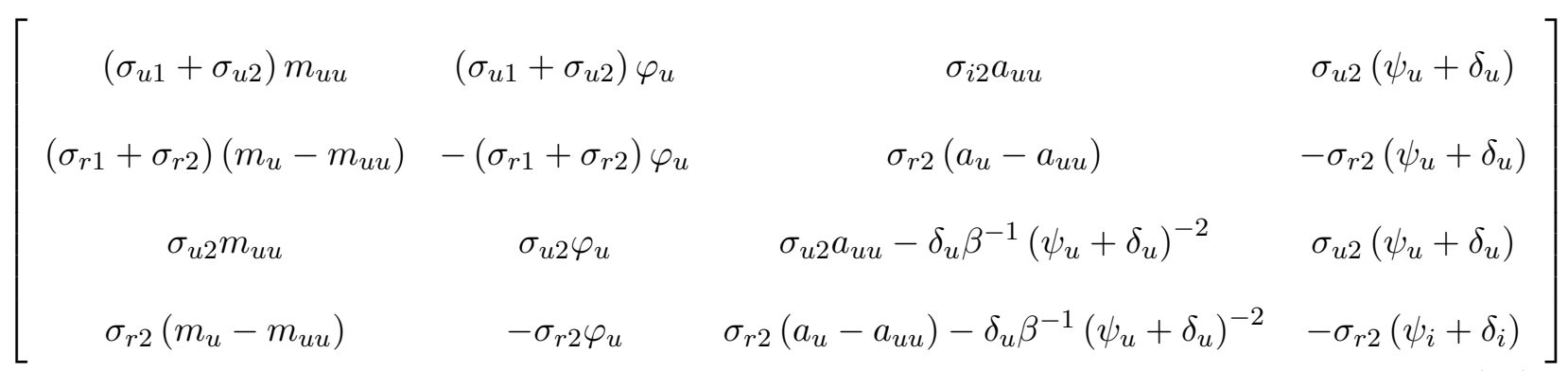

where

$$
\Phi=\left(\psi_{u}+\delta_{u}\right) \varphi_{u} \sigma_{u 2} \sigma_{r 2}\left[\sigma_{u 1} \sigma_{r 2}+\sigma_{u 1}\left(\sigma_{r 1}+\sigma_{r 2}\right)\right] m_{u} a_{u}-\frac{\varphi_{u} \delta_{u}}{\beta\left(\psi_{u}+\delta_{u}\right)}\left(\sigma_{u 1} \sigma_{u 2}\left(\sigma_{r 1}+\sigma_{r 2}\right)+\left(\sigma_{u 1}+\sigma_{u 2}\right) \sigma_{r 1} \sigma_{r 2}\right) m_{u} \geq
$$

So the determinant is positive

Differentiating $\Lambda_{1}, \Lambda_{2}, \Lambda_{3}$, and $\Lambda_{4}$, with respect to $\delta_{u}$ yields

$$
\frac{\partial \Lambda_{1}}{\partial \delta_{u}}=\sigma_{u 2} a_{u u} \leq 0
$$




$$
\begin{gathered}
\frac{\partial \Lambda_{2}}{\partial \delta_{u}}=\sigma_{r 2}\left(a_{u}-a_{u u}\right) \leq 0 \\
\frac{\partial \Lambda_{3}}{\partial \delta_{u}}=\sigma_{u 2} a_{u u}+\psi_{u} \beta^{-1}\left(\psi_{u}+\delta_{u}\right)^{-2} \\
\frac{\partial \Lambda_{4}}{\partial \delta_{u}}=\sigma_{r 2}\left(a_{u}-a_{u u}\right)+\psi_{u} \beta^{-1}\left(\psi_{u}+\delta_{u}\right)^{-2}
\end{gathered}
$$

To calculate $\partial \varphi_{u} / \delta_{u}$, the numerator matrix satisfies

$$
\left[\begin{array}{cccc}
-\sigma_{u 2} a_{u u} & \left(\sigma_{u 1}+\sigma_{u 2}\right) \varphi_{u} & \sigma_{u 2} a_{u u} & \sigma_{u 2}\left(\psi_{u}+\delta_{u}\right) \\
-\sigma_{r 2}\left(a_{u}-a_{u u}\right) & -\left(\sigma_{r 1}+\sigma_{r 2}\right) \varphi_{u} & \sigma_{r 2}\left(a_{u}-a_{u u}\right) & -\sigma_{r 2}\left(\psi_{u}+\delta_{u}\right) \\
-\sigma_{u 2} a_{u u}-\psi_{u} \beta^{-1}\left(\psi_{u}+\delta_{u}\right)^{-2} & \sigma_{u 2} \varphi_{u} & \sigma_{u 2} a_{u u}-\delta_{u} \beta^{-1}\left(\psi_{u}+\delta_{u}\right)^{-2} & \sigma_{u 2}\left(\psi_{u}+\delta_{u}\right) \\
-\sigma_{r 2}\left(a_{u}-a_{u u}\right)-\psi_{u} \beta^{-1}\left(\psi_{u}+\delta_{u}\right)^{-2} & -\sigma_{r 2} \varphi_{u} & \sigma_{r 2}\left(a_{u}-a_{u u}\right)-\delta_{u} \beta^{-1}\left(\psi_{u}+\delta_{u}\right)^{-2} & -\sigma_{r 2}\left(\psi_{u}+\delta_{u}\right)
\end{array}\right]
$$

The determinant of this matrix satisfies

$$
\Phi=\left(\sigma_{u 1}+\sigma_{r 1}\right) \sigma_{u 2} \sigma_{r 2} \varphi_{u} \beta^{-1} a_{u} \leq 0
$$

So by Cramer's rule, the comparative statics satisfy 
$\frac{\partial \varphi_{u}}{\partial \delta_{u}}=\frac{\left(\sigma_{u 1}+\sigma_{r 1}\right) \sigma_{u 2} \sigma_{r 2}\left(\psi_{u}+\delta_{u}\right) a_{u}}{m_{u}\left[\beta\left(\psi_{u}+\delta_{u}\right)^{2} \sigma_{u 1} \sigma_{u 2} \sigma_{r 2}\left(\sigma_{r 1}+2 \sigma_{r 2}\right) a_{u}-\delta_{u}\left(\sigma_{u 1} \sigma_{u 2}\left(\sigma_{r 1}+\sigma_{r 2}\right)+\left(\sigma_{u 1}+\sigma_{u 2}\right) \sigma_{r 1} \sigma_{r 2}\right)\right]} \leq 0$

as stated in Proposition 2.

\section{Impact of Central Bank Liquidity Injections}

We next turn to the predicted impact of the injections of dollar liquidity into international capital markets during the global financial crisis through the Federal Reserve's swap arrangements with other major global central banks.

In terms of our model, we consider the capital injections as analogous to an increase in $m_{r, u}$ in the decentralized market. In other words, one can consider the injections as occurring subsequent to the fall in $\delta_{u}$. As was the case empirically, the capital injections are assumed to be loans. For tractability, we assume that these swaps are to be repaid before the next period's entry into the centralized market.

The impact of the liquidity injection on an agent from a foreign country can then be represented in terms of the change in the decentralized market value function with an increase in US currency holdings, shown in equation 19, which is positive as the liquidity injections increase the set of feasible transactions in the decentralized market.

This result follows immediately from the illiquidity faced by agents in the decentralized market. However, we can also examine characteristics under which agents would be predicted to benefit more or less from the same liquidity injections. For example, differentiating $\partial V_{r} / \partial m_{r, u}$ with respect to $\lambda_{r, u}$ yields 


$$
\frac{\partial^{2} V_{r}}{\partial m_{r, u} \partial \lambda_{r, u}}=\phi_{u}\left[\left(1-\rho_{u}\right) \ell\left(q_{r, u, 1}\right) I_{r, u, 1}+\rho_{u} \ell\left(q_{r, u, 2}\right) I_{r, u, 2}\right] \geq 0
$$

Equation 54 demonstrates that the benefits of an increase in $m_{r, u}$ are increasing in $\lambda_{r, u}$, the probability of being paired with an agent from country $u$ in the decentralized market. Intuitively, the value of an increase in the payoff given this pairing is increasing in the probability of such a pairing.

Similarly, differentiating $\partial V_{r} / \partial m_{r, u}$ with respect to $\rho_{u}$, yields

$$
\frac{\partial^{2} V_{r}}{\partial m_{r, u} \partial \rho_{u}}=\phi_{u} \lambda_{r, u}\left[-\ell\left(q_{r, u, 1}\right) I_{r, u, 1}+\ell\left(q_{r, u, 2}\right) I_{r, u, 2}\right]<0
$$

since $\ell\left(q_{r, u, 1}\right) \leq \ell\left(q_{r, u, 2}\right)$. This results suggests that the benefits of an increase in $m_{r, u}$ are decreasing in $\rho_{u}$, the probability of being paired with an agent from country $u$ that is informed about the value of the risky asset in the decentralized market. Intuitively, an increase in this probability reduces the expected illiquidity in dollars an agent expects to experience in the decentralized market, decreasing the increase in expected utility from an increase in dollar liquidity.

Finally, differentiating with respect to $\ell\left(q_{r, u, 1}\right)$ yields

$$
\frac{\partial^{2} V_{r}}{\partial m_{r, u} \partial \ell\left(q_{r, u, 1}\right)}=\theta_{u} \lambda_{r, u, 1} I_{r, u, 1}>0
$$

The solution for $\ell\left(q_{r, u, 2}\right)$ is similar. This result suggests that the benefits of an increase in $m_{r, u}$ are increasing in $\ell\left(q_{r, u, 1}\right)$, the dollar illiquidity experienced by an agent in a type 1 meeting. Intuitively, an increase in illiquidity raises the increase in expected utility from an increase in dollar liquidity. 


\section{Conclusion}

This paper derives an international centralized and decentralized market model. Our results show that it is possible for a deterioration in US asset values, analogous to the meltdown experienced during the global financial crisis in US real estate and asset-backed securities, to result in an appreciation in the dollar exchange rate, as was observed at the crisis apex. The deterioration in the values of other dollar assets reduces the availability of dollars for transactions purposes and raises the demand for other dollar assets, such as cash, that can substitute in providing these liquidity services.

Our model predicts that the benefits of swap arrangements, such as those pursued by the Federal Reserve swap arrangements are likely to be dependent on a number of agent characteristics. The benefits are shown to be increasing in the probability of needing to transact in dollars, the opaqueness of an agent's asset portfolio, and its illiquidity. In a companion paper, Rose and Spiegel (2012), we demonstrate that auctions of dollar assets obtained in swaps with the Federal Reserve by foreign central banks disproportionately benefited countries that were more exposed to the United States through either trade linkages or asset exposure. We also find that several of the important announcements concerning the international swap programs disproportionately benefited countries exhibiting greater asset opaqueness. As such, it appears that these swap programs had the benign impact of delivering the greatest assistance to the most distressed countries in the global economy.

The Lester, Postlewaite, and Wright (2012) extension of the model of Lagos and Wright (2005) to allow for endogenous information acquisition for a closed economy demonstrates that such an extension raises the possibility of a multiplicity of equilibria. Under such circumstances, policy interventions that can restrict outcomes to the set of more desirable equilibria could be welfare enhancing. In principle, one could extend the open-economy model in that direction as well and perhaps demonstrate even greater potential gains from international interventions during crisis episodes similar to the swaps undertaken by the Federal Reserve. We leave such an extension for 
future work. 


\section{References}

Aizenman, J., And G. K. Pasricha (2010): "Selective Swap Arrangements and the Global Financial Crisis:," International Review of Economics and Finance, 19(3), 353-365.

Brigo, D., M. Predescu, and A. Capponi (2010): "Credit Defaqult Swaps Liquidity Modeling: A Survey," mimeo, Cornell University.

Geromichalos, A., and I. Simonovska (2010): "Asset Liquidity and Home Bias," mimeo.

Giovannini, A. (1988): "Exchange Rates and Traded Goods Prices," Journal of International Economics, 24, 105-116.

Goldberg, L., And C. Tille (2008): "Vehicle Currency Use in International Trade," Journal of International Economics, 76, 177-192.

Krugman, P. (2007): "Will there be a dollar crisis?," Economic Policy, 22(51), 435-67.

Lagos, R., and G. Rocheteau (2008): "Money and Capital as Competing Media of Exchange," Journal Economic Theory, 142(1), 247-258.

Lagos, R., And R. Wright (2005): "A Unified Framework for Monetary Theory and Policy Analysis," Journal of Political Economy, 113(3), 463-484.

Lester, B., A. Postlewaite, and R. Wright (2012): "Information, Liquidity, Asset Prices and Monetary Policy," forthcoming, Review of Economic Studies.

LIU, Q. (2010): "Goods Market Frictions and Real Exchange Rate Puzzles," mimeo.

Obstfeld, M., J. C. Shambaugh, and A. Taylor (2009): "Financial Instability, Reserves, and Central Bank Swap Lines in the Panic of 2008," American Economic Review: Papers and Proceedings, 99(2), 480-486.

Rey, H. (2001): "International Trade and Currency Exchange," Review of Economic Studies, 68, 443-464.

Rose, A. K., And M. M. Spiegel (2012): "Dollar Illiquidity and Central Bank Swap Arrangements During the Global Financial Crisis," forthcoming, Journal of International Economics.

SwobodA, A. K. (1968): "The Euro-Dollar Market: An Interpretation," Princeton Essays in International Finance, 64. 
Table 1: International swap arrangements (2007-2008)

\begin{tabular}{|c|c|c|}
\hline Announcement Type & Date & Details \\
\hline $\begin{array}{l}\text { Swap lines introduced } \\
\text { with ECB and SNB }\end{array}$ & $12 / 12 / 2007$ & $\begin{array}{l}\text { Establishment of foreign exchange swap lines. Authorization of temporary } \\
\text { reciprocal currency arrangements with the European Central Bank and Swiss } \\
\text { National Bank, providing } \$ 20 \text { billion and } \$ 4 \text { billion respectively.Arrangements } \\
\text { authorized for up to six months. }\end{array}$ \\
\hline $\begin{array}{l}\text { Swap lines introduced } \\
\text { with BOJ, BOE, and Bank } \\
\text { of Canada. Funds } \\
\text { increased for the ECB and } \\
\text { SNB. }\end{array}$ & $9 / 18 / 2008$ & $\begin{array}{l}\text { New swap facilities authorized with the Bank of Japan for amounts up to } \$ 60 \\
\text { billion, the Bank of England for up to } \$ 40 \text { billion, and the Bank of Canada for up } \\
\text { to } \$ 10 \text { billion. In addition, swap line provisions increased to } \$ 110 \text { for the } \\
\text { European Central Bank and } \$ 27 \text { billion to the Swiss National Bank. Arrangements } \\
\text { authorized through January } 30,2009\end{array}$ \\
\hline $\begin{array}{l}\text { Swap lines introduced } \\
\text { with Australia, Sweden, } \\
\text { Denmark, and Norway. }\end{array}$ & $9 / 24 / 2008$ & $\begin{array}{l}\text { Currency swap facilities established in amounts of up to } \$ 10 \text { billion each by the } \\
\text { Reserve Bank of Australia and Sveriges Riksbank and amounts of up to } \$ 5 \text { billion } \\
\text { each by Danmarks Nationalbank and the Norges Bank. Arrangements authorized } \\
\text { through January } 30,2009\end{array}$ \\
\hline $\begin{array}{l}\text { Unlimited swaps } \\
\text { announced with ECB, } \\
\text { BOE, and SNB. }\end{array}$ & $10 / 13 / 2008$ & $\begin{array}{l}\text { Funds provided to swap facilities with the Bank of England, the European Central } \\
\text { Bank, and the Swiss National Bank increased to "accommodate whatever quantity } \\
\text { of U.S. dollar funding is demanded". Arrangements were authorized through April } \\
30,2009 \text {. }\end{array}$ \\
\hline $\begin{array}{l}\text { Unlimited Swaps } \\
\text { announced with the BOJ }\end{array}$ & $10 / 14 / 2008$ & $\begin{array}{l}\text { Unlimited swap arrangement announced with the Bank of Japan a day after the } \\
\text { same announcement was made regarding swap lines with major central bank in } \\
\text { Europe. Arrangements authorized though April 30,2009 }\end{array}$ \\
\hline $\begin{array}{l}\text { Swap lines introduced } \\
\text { with the Reserve Bank of } \\
\text { New Zealand }\end{array}$ & $10 / 28 / 2008$ & $\begin{array}{l}\text { New swap line of up to } \$ 15 \text { billion with the Reserve Bank of New Zealand } \\
\text { announced. Arrangement authorized through April 30, } 2009 .\end{array}$ \\
\hline $\begin{array}{l}\text { Swap Line Introduced } \\
\text { with Brazil, Mexico, } \\
\text { Korea, and Singapore. }\end{array}$ & $10 / 29 / 2008$ & $\begin{array}{l}\text { New swap facilities established in amounts of up to } \$ 30 \text { billion each by the Banco } \\
\text { Central do Brazo, the Banco de Mexico, the Bank of Korea, and the Monetary } \\
\text { Authority of Singapore. Authorized through April 30, } 2009 \text {. }\end{array}$ \\
\hline
\end{tabular}

Note: Announcements concerning changes in international swap arrangements pursued by the Federal Reserve and major central banks during the global financial crisis.

Source: Federal Reserve Board of Governors 
Figure 1: Stock market volatility and EUR-USD bilateral exchange rates (2007-2009)

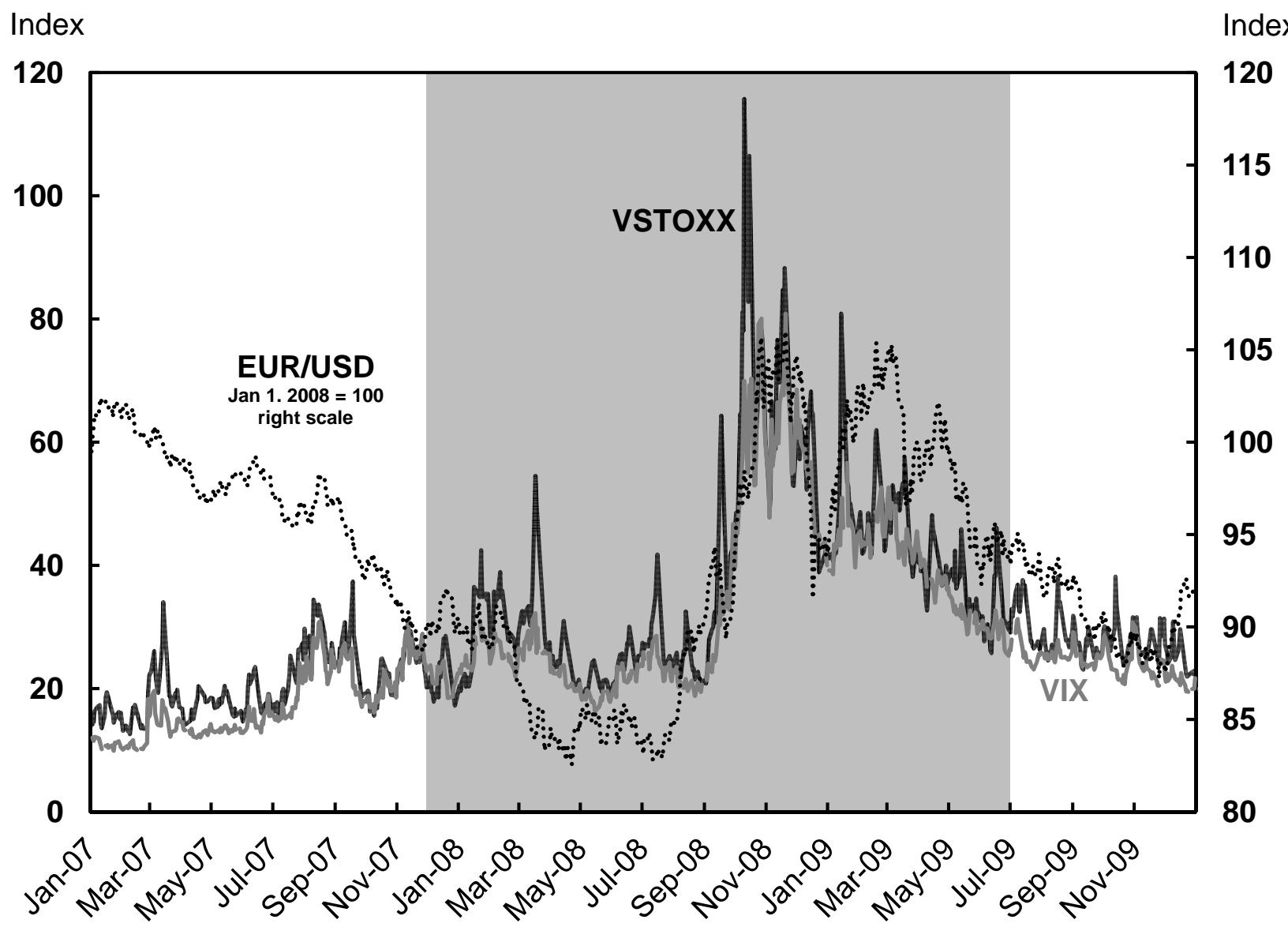

Shaded bar represents US NBER recession dates.

VIX and VSTOXX indices represent volatilities in US and European equity markets respectively. EUR-USD represents the nominal euro/dollar exchange rate.

Source: Bloomberg 
Figure 2: CDS spreads (2007-2009)

Basis Points

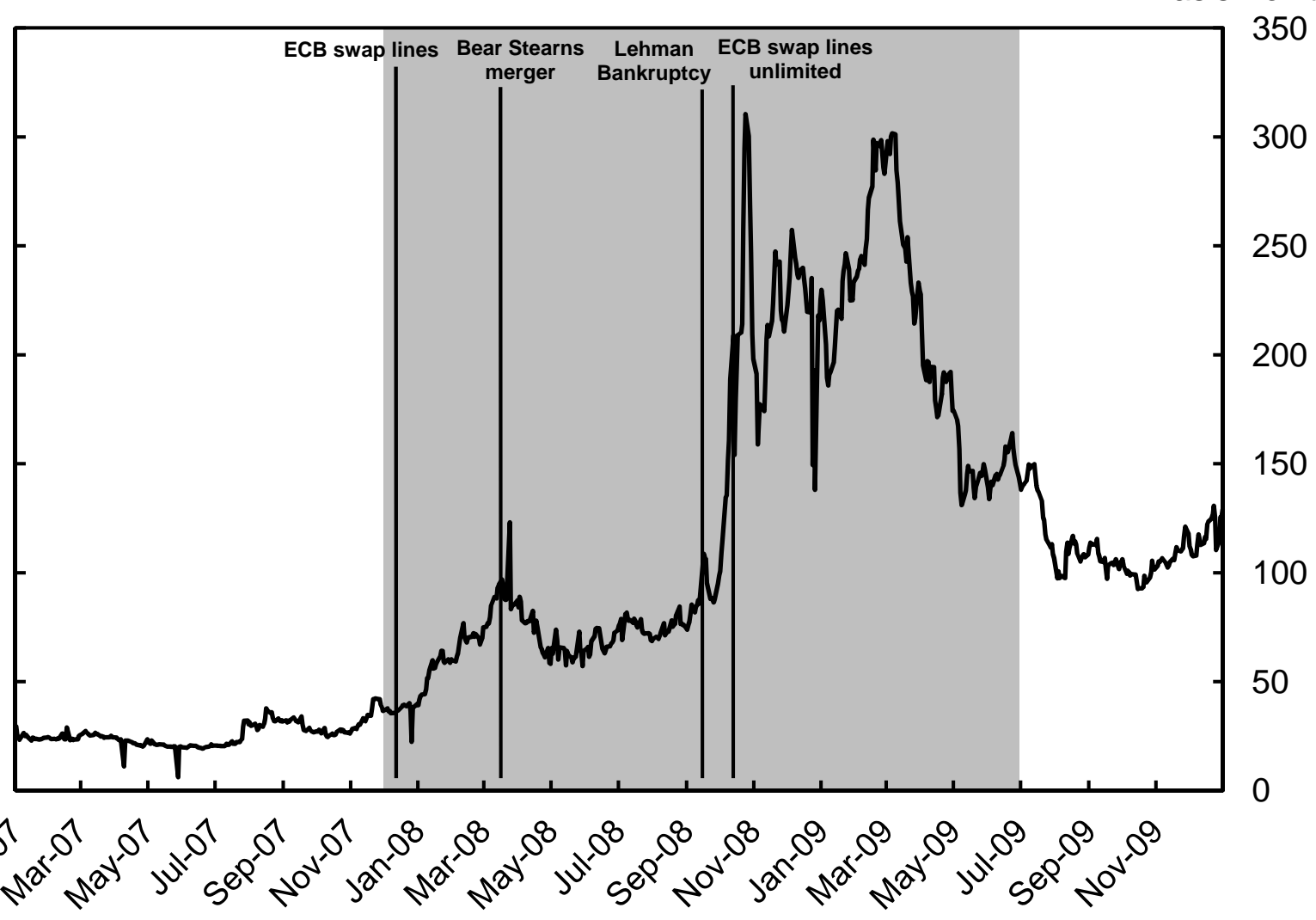

Shaded bar represents US NBER recession dates.

Mean CDS spreads for 13 OECD countries.

Source: Bloomberg 